\title{
RESTRICÃO HÍDRICA ATRAVÉS DE DIFERENTES AGENTES OSMÓTICOS: EFEITO NA QUALIDADE DE SEMENTES DE SOJA
}

TAVARES, L. C. ${ }^{1}$; BRUNES, A. P. ${ }^{2}$; MENDONÇA, A. $0 .{ }^{3}$; CAVALCANTE, J. A. ${ }^{4}$; MENEGHELlO, G. E ${ }^{5}$.

'Dr Syngenta Seeds

${ }^{2}$ Prof Dr Universidade Federal do Rio Grande do Sul

${ }^{3}$ Prof Dr Instituto Federal Farroupitha

${ }^{4}$ MsC. Universidade Federal de Pelotas

${ }^{5}$ Dr Universidade Federal de Pelotas

Palavras-chave:embebição, Glycine $\max$ (L.) Merrill, potencial

\section{Resumo}

A limitação de água durante a germinação pode diminuir a velocidade da germinação ou até mesmo impedi-la, já que a água é fundamental no processo de ativação metabólica na retomada do crescimento do embrião. 0 objetivo deste trabalho foi avaliar a influência de agentes e potencias osmóticos na germinação de sementes de soja. 0 delineamento experimental utilizado foi inteiramente casualizados em esquema fatorial $5 \times 4$ (cinco agentes indutores e quatro concentrações osmóticas), sendo os agentes indutores o PEG 6000, manitol, cloreto de sódio, cloreto de cálcio, e cloreto de magnésio, e os potenciais osmóticos de $0 ;-0,3 ;-0,6$; e - 0,9 $\mathrm{MPa}$, com quatro repetições. Foi avaliado a primeira contagem de germinação, germinação, plântulas normais e sementes mortas. Conclui-se que a germinação de sementes de soja reduz com o aumento da restrição hídrica e todos os solutos estudados afetam o vigor das sementes. A solução de manitol é a menos drástica na germinação e no número de plântulas anormais em potenciais até $-0,9 \mathrm{MPa}$, já a solução de PEG 6000 é mais prejudicial na viabilidade de sementes de soja.

\section{INDUCTION OF WATER STRESS THROUGH DIFFERENT OSMOTIC AGENTS: EFFECT ON QUALITY OF SOYBEAN SEEDS}

Keywords: imbibition, Glycine $\max$ (L.) Merrill, osmotic potential.

\begin{abstract}
The limitation of water during germination can decrease the speed of germination or even stop it, since water is fundamental in the process of metabolic activation in the resumption of embryo growth. The objective of this study was to evaluate the influence of agents and osmotic potential and germination of soybean seeds. The experimental design was completely randomized in a factorial AxB, factor A: inducing agents: PEG 6000, mannitol, sodium chloride, calcium chloride, and magnesium chloride, and factor B: osmotic potential 0; $-0.3 ;-0.6$ and $-0.9 \mathrm{MPa}$, with four replications. The first count of germination, germination, abnormal seedlings and dead seeds. We conclude that the germination of soybean seeds reduces with increasing water restriction and all solutes studied affect seed vigor. The mannitol solution is less drastic in germination and the number of abnormal seedling in potential up to $-0.9 \mathrm{MPa}$, since the solution of PEG 6000 is more harmful on the viability of soybean seeds.
\end{abstract}




\section{INTRODUÇÃO}

O Brasil, atualmente, é o segundo maior produtor de soja do mundo, com cerca de 119 milhóes de toneladas produzidas e 35 milhóes de hectares cultivados na safra 2017/2018 (CONAB, 2018). Para atender essa demanda, é necessário o uso de sementes de qualidade superior, capazes de possibilitar um estabelecimento rápido e uniforme, proporcionando um adequado estande no campo, consequentemente, possibilitando elevadas produtividades.

No entanto, em muitas regiōes brasileiras, na época de semeadura, ocorrem com frequência períodos de estiagem, sendo esta uma das causas mais comuns do baixo percentual de germinação e emergência de plântulas no campo (PESKE; DELOUCHE, 1985). A primeira etapa da germinação ocorre com a absorção de água pela semente, mediante embebição (BEWLEY et al., 2013). Porém, se o fornecimento de água à semente for limitado, a velocidade de germinação diminuirá ou até inviabilizara a emergência.

A capacidade da semente de germinar e se desenvolver em situaçóes de baixa disponibilidade hídrica varia de acordo com a espécie, com a genética e com a qualidade fisiológica que as mesmas possuem. Assim, empresas produtoras de sementes procuram detectar lotes com desempenho superior, capazes de germinar em condiçóes de estresse ambiental, tal como estiagem na época de semeadura (SILVA et al., 2006).

O déficit hídrico é um dos principais fatores ambientais limitantes da germinação, sendo que para cada espécie existe um valor de potencial hídrico abaixo do qual a germinação não ocorre (MARCOS FILHO, 2015). A habilidade da semente germinar sob amplo limite de condiçóes adversar pode ser atribuída, em parte, à manifestação de seu vigor, além de depender, entre outros fatores, das condiçôes ambientais encontradas no local onde foi semeada. Restrição hídrica, em momentos subsequentes a semeadura, podem ser encontradas de forma frequente no campo, e a semente deve ser vigorosa para conseguir emergir mesmo nestas condiçóes adversas (MARCOS FILHO, 2015).

Outra forma de verificar o efeito do déficit hídrico em sementes é a utilização de soluções salinas, tais como $\mathrm{NaCl}, \mathrm{KCl}$ e $\mathrm{MgCl}_{2}$, sendo que o estresse hídrico é devido ao efeito osmótico, ou seja, à seca fisiológica produzida (TOBE et al., 2000). As sementes são sensíveis aos efeitos da salinidade e, quando semeadas em soluçôes salinas, devido à diminuição do potencial osmótico do substrato, observa-se, inicialmente, uma diminuição na absorção de água (FERREIRA; REBOUÇAS, 1992; AMORIM et al., 2002). Entretanto, o efeito da redução do potencial osmótico sobre as sementes e plântulas de soja depende da qualidade inicial das sementes, do tipo de sal e sua concentração (MORAES; MENEZES, 2003).

Contudo, ainda existe a carência de pesquisas relacionados a germinação e vigor de sementes de soja sob deficiência hídrica, utilizando-se diferentes soluçóes osmóticas, a fim de se definir as diferenças existentes entre as mesmas na qualidade das sementes. Nesse contexto, objetivou-se avaliar os efeitos do estresse hídrico induzido por agentes osmóticos, em diferentes potenciais, sobre a germinação e vigor de sementes de soja.

\section{MATERIAL E MÉTODOS}

O experimento foi desenvolvido no Laboratório Didático de Análise de Sementes da Faculdade de Agronomia Eliseu Maciel FAEM/UFPel e a cultivar de Soja utilizada foi a NK7059 RR. O delineamento experimental utilizado foi inteiramente casualizados em esquema fatorial 5x4 (cinco agentes indutores e quatro concentraçóes osmóticas), sendo os agentes indutores o PEG 6000, manitol, cloreto de sódio, cloreto de cálcio, e cloreto de magnésio, e os potenciais osmóticos de 0 ; $-0,3$; -0,6; e - $0,9 \mathrm{MPa}$, com quatro repetiçóes para cada tratamento.

Para o cálculo da quantidade de manitol, $\mathrm{MgCl}_{2}$, $\mathrm{NaCl}$ e $\mathrm{CaCl}_{2}$ a ser adicionada para obtençáo das tensões estudadas, utilizou-se a fórmula de Van't Hoff (HILLEL, 1971), ou seja: $\Psi$ os = - R.T.C; onde: $\Psi$ os: potencial osmótico (atm); R: constante geral dos gases perfeitos (0,082 atm.l.mol.oK $\left.{ }^{-1}\right)$; T: temperatura (oK); $\mathrm{C}$ : concentração $\left(\mathrm{mol} \mathrm{L}^{-1}\right)$. Na Tabela 1 encontramse as concentraçóes dos agentes osmóticos utilizados, referentes aos respectivos níveis de potencial osmótico resultantes, sendo as tensóes de PEG 6000 preparadas segundo as recomendaçóes de Villela et al. (1991). 
Tabela 1. Concentrações dos agentes osmóticos utilizados para obter cada nível de potencial osmótico.

\begin{tabular}{llllll}
\hline $\begin{array}{l}\text { Potencial } \\
\text { Osmótico } \\
(\mathrm{Mpa})\end{array}$ & \multicolumn{5}{c}{ Agente Osmótico } \\
\cline { 2 - 6 } & Manitol & $\mathrm{CaCl} 2$ & $\mathrm{NaCl}$ & $\mathrm{MgCl}_{2}$ & $\begin{array}{l}\mathrm{PEG} \\
6000\end{array}$ \\
\hline \multicolumn{5}{c}{} \\
& & & & \\
\hline$-0,3$ & 22,29 & 7,98 & 4,20 & 6,85 & 151,40 \\
$-0,6$ & 44,58 & 15,95 & 8,40 & 13,71 & 223,66 \\
$-0,9$ & 66,87 & 23,94 & 12,60 & 20,56 & 279,29 \\
\hline
\end{tabular}

A avaliação da qualidade fisiológica das sementes foi realizada pelos seguintes testes:

Germinação $(G)$ : realizada com quatro repetiçôes de 50 sementes para cada nível de vigor, as quais foram colocadas em substrato papel germitest previamente umedecido em água destilada para o potencial de 0 $\mathrm{MPa}$ e com as respectivas soluçóes para as demais concentrações, na quantidade equivalente a 2,5 vezes a sua massa seca, e mantidas em germinador à temperatura constante de $25^{\circ} \mathrm{C}$ e luz constante. As avaliações foram efetuadas no oitavo dia após a semeadura conforme as Regras para Análise de Sementes (BRASIL, 2009).

Primeira contagem da germinação (PCG): foi conduzida em conjunto com o teste de germinação e avaliada no quinto dia após a semeadura (BRASIL, 2009).

Plântulas anormais (PA) e mortas (SM): realizada em função do teste de germinação, sendo expressa em porcentagem de plântulas anormais e mortas (BRASIL, 2009).

Os dados foram analisados quanto à normalidade e homocedasticidade e, posteriormente, submetidos à análise de variância $(\mathrm{p}<0,05)$. Sendo significativa a probabilidade "F", o fator indutor foi comparado pelo teste Tukey e o fator potencial osmótico submetidos à regressão polinomial, ambos a $5 \%$ de probabilidade. Para análise estatística utilizou-se o software $\mathrm{R}^{\odot}$, versão 3.1.2 (R CORE, 2014).

\section{RESULTADOS E DISCUSSÃO}

Observou-se que houve interação entre os níveis de potencial osmótico e agentes indutores de deficiência hídrica estudados. A diferença entre as médias dos solutos em cada potencial osmótico, para cada variável analisada, está apresentado na Tabela 2, e a variação do potencial osmótico dentro de cada soluto foi representada través de gráficos de regressão polinomial nas Figuras 1A a $1 \mathrm{D} 4$.

Tabela 2. Primeira contagem do teste de germinação (PCG), germinação (G), plântulas anormais e sementes mortas para diferentes soluções osmóticas dentro de cada nível de potencial.

\begin{tabular}{|c|c|c|c|c|c|}
\hline Nível & Solução & PCG & G & Anormais & Mortas \\
\hline $\begin{array}{l}\operatorname{de} \Psi \\
\text { os }^{*} \\
(\mathrm{MPa}) \\
\end{array}$ & & & $(\%)$ & & \\
\hline 0,0 & Testemunha** & 83 & 88 & 5,22 & 3,44 \\
\hline \multirow[t]{5}{*}{$-0,3$} & Manitol & $\begin{array}{l}52,11 \\
a^{* * *}\end{array}$ & $\begin{array}{l}76,78 \\
\mathrm{a}\end{array}$ & $15,77 \mathrm{c}$ & $4,11 \mathrm{~b}$ \\
\hline & $\mathrm{CaCl} 2$ & $33,33 \mathrm{~b}$ & $\begin{array}{l}78,67 \\
\mathrm{a}\end{array}$ & $14,00 \mathrm{c}$ & $5,00 \mathrm{~b}$ \\
\hline & $\mathrm{NaCl}$ & $37,11 \mathrm{~b}$ & $\begin{array}{l}66,00 \\
b\end{array}$ & $23,44 \mathrm{bc}$ & $7,22 \mathrm{~b}$ \\
\hline & $\mathrm{MgCl} 2$ & $0,00 \mathrm{c}$ & $\begin{array}{l}3,44 \\
\mathrm{~d}\end{array}$ & 88,47 a & $4,00 \mathrm{~b}$ \\
\hline & PEG 6000 & $1,22 \mathrm{c}$ & $\begin{array}{l}14,78 \\
\mathrm{c}\end{array}$ & $31,42 \mathrm{~b}$ & $20,33 \mathrm{a}$ \\
\hline \multirow[t]{5}{*}{$-0,6$} & Manitol & $1,56 \mathrm{a}$ & $\begin{array}{l}23,89 \\
a\end{array}$ & $67,44 \mathrm{~b}$ & $5,33 \mathrm{~b}$ \\
\hline & $\mathrm{CaCl} 2$ & $0,00 \mathrm{a}$ & $0,00 \mathrm{~b}$ & 87,78 a & $8,88 \mathrm{~b}$ \\
\hline & $\mathrm{NaCl}$ & $0,33 \mathrm{a}$ & $\begin{array}{l}16,44 \\
\mathrm{a}\end{array}$ & $71,22 \mathrm{~b}$ & $9,00 \mathrm{~b}$ \\
\hline & $\mathrm{MgCl} 2$ & $0,00 \mathrm{a}$ & $0,00 \mathrm{~b}$ & 84,33 a & $12,33 \mathrm{~b}$ \\
\hline & PEG 6000 & $0,00 \mathrm{a}$ & $0,11 \mathrm{~b}$ & $25,44 \mathrm{c}$ & $75,00 \mathrm{a}$ \\
\hline \multirow[t]{5}{*}{$-0,9$} & Manitol & $0,00 \mathrm{a}$ & 0,56 a & $84,44 \mathrm{a}$ & $11,67 d$ \\
\hline & $\mathrm{CaCl} 2$ & $0,00 \mathrm{a}$ & $0,00 \mathrm{a}$ & $67,67 \mathrm{~b}$ & $29,00 \mathrm{c}$ \\
\hline & $\mathrm{NaCl}$ & $0,00 \mathrm{a}$ & $0,00 \mathrm{a}$ & 84,67 a & $12,00 \mathrm{~d}$ \\
\hline & $\mathrm{MgCl} 2$ & $0,00 \mathrm{a}$ & 0,00 a & $35,22 \mathrm{~d}$ & $61,44 \mathrm{a}$ \\
\hline & PEG 6000 & $0,00 \mathrm{a}$ & $2,22 \mathrm{a}$ & $47,11 \mathrm{c}$ & $49,44 \mathrm{~b}$ \\
\hline $\begin{array}{l}\text { CV } \\
(\%)\end{array}$ & & 13,5 & 11,1 & 16,6 & 30,0 \\
\hline
\end{tabular}

* Nível de $\Psi$ osmótico; ${ }^{* *}$ a testemunha, água destilada, apresentou resultados iguais para todas as soluções osmóticas; ***Médias seguidas por letras distintas, dentro de cada nível de potencial, diferem entre si pelo teste de Tukey a $5 \%$ de probabilidade.

Verificou-se na Figura 1A, para todos os solutos estudados, que a diminuição do potencial osmótico reduziu linearmente a percentagem de sementes germinadas na determinação da primeira contagem 
da germinação (PCG). Essa redução foi mais acentuada nas soluçóes de $\mathrm{Manitol}, \mathrm{CaCl}$ e $\mathrm{MgCl}_{2}$, respectivamente, onde para cada $-0,1 \mathrm{MPa}$ de aumento no potencial tem-se uma redução da germinação na ordem de 9,98, 9,52 e 9,41\%. Em estudo semelhante submetendo sementes de pinho cuiabano (Schizolobium amazonicum) a diferentes agentes e potenciais osmóticos foi observado que a germinaçáo foi reduzida de forma linear, entretanto a solução de PEG 6000 e $\mathrm{CaCl}_{2}$ foram as que ocasionaram maior restrição a germinação (BRAGA et al., 2008). Outros autores também encontraram redução da germinação de sementes de soja com o aumento do potencial hídrico (BRACCINI et al., 1996) e também para sementes de feijão (MACHADO NETO et al., 2006, CUSTÓDIO et al., 2009).

Comparando os diferentes agentes indutores em cada um dos potenciais estudados, contatou-se que no potencial de $-0,3 \mathrm{MPa}$ o manitol foi o menos afetou a germinação, enquanto o $\mathrm{MgCl}_{2}$ e PEG 6000 ocasionaram maior restrição (Tabela 2 ). Nos potenciais de -0,6 e -0,9 MPa não houve diferença significativa entre os solutos estudados, sendo que no potencial mais baixo, onde a restrição hídrica foi maior, não ocorreu germinação durante a avaliação de PCG. Em estudo semelhante conduzido com sementes de soja, houve germinação durante a avaliaçáo da primeira contagem da germinação até o potencial de -0,9 MPa quando utilizado solução de manitol (BRACCINI et al. 1996), divergindo dos resultados deste trabalho. Contudo, ressalta-se que a resposta ao potencial osmótico é dependente de características genéticas da cultivar e do vigor das sementes, e como foi constatado por outros autores, a faixa entre 0,0 até -0,5 $\mathrm{MPa}$ apresenta-se com uma alternativa viável para estimar o vigor das sementes.

Resultado semelhante foi observado no teste de germinação $(G)$ onde foi constatada uma redução linear da germinação com a redução do potencial osmótico para todos os agentes indutores testados. A maior restrição foi observada quando utilizadas soluçôes de $\mathrm{CaCl}_{2}$, Manitol e $\mathrm{NaCl}$, onde a redução foi na ordem de $11,4,10,5$ e $10,4 \%$ para cada $-0,1 \mathrm{MPa}$ aumentados no potencial osmótico, respectivamente (Figura 1B). Comparando os diferentes agentes indutores, de modo geral a restrição da germinação foi mais severa quando foram utilizados os sais $\mathrm{MgCl}_{2}$ e PEG 6000 (Tabela 2). Também para Braccini et al. (1996), a solução de PEG 6000 ocasionou maior restrição da germinação nos potenciais estudados. No mesmo estudo, os autores encontraram que as soluçóes de manitol e $\mathrm{NaCl}$ restringiram menos a germinação do que a solução de PEG 6000 para potenciais de até $-0,6 \mathrm{MPa}$, corroborando com a presente pesquisa, onde as soluçóes de manitol e $\mathrm{NaCl}$ possibilitaram uma maior percentagem de germinaçáo no potencial de -0,6 MPa sendo menos prejudicial às sementes no que se refere a sua qualidade fisiológica.

Outros autores encontraram restrição menos severa na germinaçáo quando utilizaram solução de $\mathrm{NaCl}$ (BRAGA et al., 2008), e manitol em sementes de feijão (MACHADO NETO et al., 2006), entretanto, neste último, a solução de $\mathrm{NaCl}$ foi a que ocasionou menor germinação das sementes de feijão devido ao efeito prejudicial ocasionado pela presença de íons $\mathrm{Na}+$. Não houve diferença significativa entre os solutos estudados para a variável germinação quando em potencial de -0,9 Mpa (Figura 1B).

Quanto a porcentagem de plântulas anormais, as soluçóes de $\mathrm{MgCl}_{2}$ e $\mathrm{CaCl}_{2}$ foram as que apresentaram resultados nas concentraçóes mais baixas (-0.9 Mpa), ou seja, em condiçóes de menor restrição hídrica (Figura 1C). A diminuição do potencial hídrico acarretou na diminuiçáo na percentagem de plântulas anormais, sendo o comportamento para esses solutos ajustado por uma equação polinomial quadrática. A redução do número de plântulas anormais se deve ao fato do maior número de sementes que não iniciaram o processo germinativo devido ao baixo potencial, sendo essas expressadas em porcentagem de sementes mortas. As soluçôes de $\mathrm{NaCl}$, manitol e PEG 6000 ocasionaram um aumento linear no percentual de plântulas anormais a medida que o potencial osmótico foi reduzido, esse efeito foi menos drástico quando se utilizou $\mathrm{NaCl}$ e mais drástico para PEG 6000 (Figura $1 \mathrm{C)}$. 

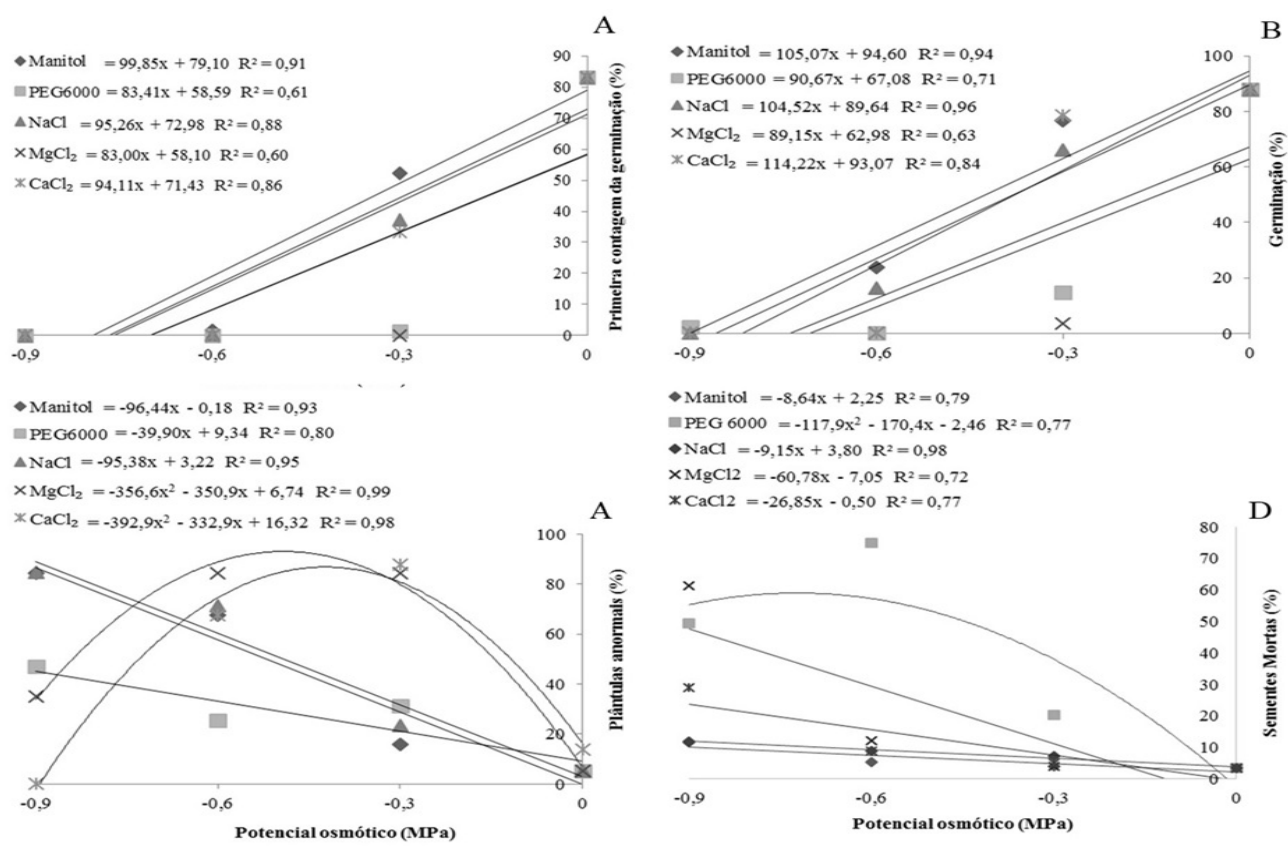

Figura 1. Primeira contagem de germinação (A), germinação (B), plântulas anormais (\%) e sementes mortas (D) de sementes de soja cultivar NK7059 RR, expostas a deficiência hídrica induzida por diferentes concentrações de Manitol, PEG 6000, $\mathrm{NaCl}, \mathrm{MgCl}_{2}, \mathrm{CaCl}_{2}$, dentro de cada potencial hídrico estudado.

A diferença observada nas tendências, representadas pelas equações de primeiro e segundo grau, nas diferentes soluçóes utilizadas, provavelmente deve-se ao fato de que as soluçôes de $\mathrm{MgCl}_{2}$ e $\mathrm{CaCl}_{2}$ apresentaram 93 e $87 \%$ de plântulas anormais, nos potenciais osmóticos de $-0,49$ e $-0,42 \mathrm{MPa}$, respectivamente, sendo que acima disso a restrição foi suficientemente forte a ponto de tornar-se tóxica, elevando a taxa de sementes mortas (Figura 1C). Já as soluçôes de manitol, PEG 6000 e NaCl, o aumento na porcentagem de plântulas anormais foi de 9,6; 4,0 e 9,5\% para cada -0,1Mpa, não atingindo equivalente nível de toxicidade nas concentraçóes utilizadas. Em estudo com sementes de melancia submetidas a estresse hídrico, foi verificado que as plântulas se apresentaram mais sensíveis a solução de $\mathrm{NaCl}$ do que os demais solutos estudados (SOUSA et al., 2009), concordando com os resultados encontrados no presente trabalho.

Com relação ao número de sementes mortas (Figura 1D), constatou-se maior resultado quando utilizada a solução de PEG 6000, apresentando redução a partir do ponto de máxima localizado em -0,72 $\mathrm{MPa}$, seguido da soluçáo de $\mathrm{MgCl}_{2}$ que obteve um aumento linear para essa variável, sendo mais prejudicial que os demais solutos no potencial de $-0,9 \mathrm{MPa}$. A solução de manitol foi a que apresentou menor percentual de sementes mortas, sendo menos prejudicial às mesmas.
Resultado semelhantes foram constatados também por Braccini et al. (1996), onde sementes de soja tiveram seu vigor menos afetado pela soluçáo de manitol, e por Custódio et al. (2009), que concluíram que o manitol é o soluto menos drástico para obtenção de condiçóes de estresse hídrico.

A primeira etapa da germinação se processa com a absorção de água pela semente, mediante embebiçáo, cuja velocidade de absorção é determinada pela sua disponibilidade, pela composição química da semente, permeabilidade do tegumento, temperatura e qualidade fisiológica da semente. A água absorvida promove a reidratação dos tecidos e, consequentemente, há intensificação da respiração e das demais atividades metabólicas, que culminam com o fornecimento de energia e nutrientes necessários para a retomada de crescimento por parte do eixo embrionário (MARCOS FILHO, 2015).

O período inicial de embebição é crítico para a germinação. Assim, potenciais osmóticos muito negativos atrasam e diminuem a germinação, havendo um nível mínimo de umidade que a semente deve atingir para iniciar e completar o processo, o qual depende da composição química e permeabilidade desta (VERSLUES et al., 2006).

Altas concentraçóes salinas afetam a germinação não só dificultando a cinética de absorção de água, mas 
também facilitando a absorção de íons em quantidade tóxica nas células das sementes embebidas, assim, o aumento da concentração salina torna-a cada vez menos disponível para as plantas (MUNNS, 2002). A inibição do crescimento ocasionada pela salinidade, segundo Tobe et al. (2000), se deve tanto ao efeito osmótico, ou seja, à "seca fisiológica” produzida, como ao efeito tóxico, resultante da concentração de íons no protoplasma. Estas respostas bioquímicas irão refletir diretamente na germinação (SANTOS et al., 2011).

Segundo Tester e Davénport (2003), a salinidade, tanto dos solos como das águas, é uma das principais causas da queda de rendimento das culturas em regióes áridas e semiáridas, porém, os efeitos dependem de fatores como espécie, cultivar, tipos de sais, intensidade e duração do estresse salino, manejo cultural e da irrigação e condições edafoclimáticas.

Assim, os estudos relacionados com a resposta germinativa de sementes submetidas à condição de estresses artificiais são ferramentas para um melhor entendimento da capacidade de sobrevivência e adaptação destas espécies em condições de estresses naturais, como seca e solos salinizados, comuns em regiôes agrícolas, bem como a avaliaçáo da sensibilidade dessas espécies em estudo para um melhor entendimento da agressividade e estratégias de dominância das mesmas em ambientes adversos.

\section{CONCLUSÃO}

A germinação de sementes de soja reduz com o aumento da restrição hídrica.

A solução de manitol como agente indutor de restrição hídrica é a menos drástica na germinação de sementes e no número de plântulas anormais em potenciais até -0,9 MPA, já a solução de PEG 6000 apresenta efeito prejudicial mais acentuado na viabilidade de sementes de soja.

\section{LITERATURA CITADA}

AMORIM, J. R. A.; FERNANDES, P. D.; GHEYI, H. R.; AZEVEDO, N. C. Efeito da salinidade e modo de aplicação da água de irrigação no crescimento e produção de alho. Pesquisa Agropecuária Brasileira, v.37, n.2, p.167-176, 2002.

BEWLEY, J. D. BLACK, M. Seeds: physiology of development and germination. 1.ed. New York: Plenum, 1994, 445p.
BRACCINI, A. L., RUIZ, H. A., BRACCINI, M. C. L.; REIS, M. S. Germinaçáo e vigor de sementes de soja sob estresse hídrico induzido por soluçóes de cloreto de sódio, manitol e polietilenoglicol. Revista Brasileira de Sementes, v.18, n.1, p.1016, 1996.

BRAGA, L. F.; SOUSA, M. P.; CESARO, A. S.; LIMA, G. P. P.; GONÇALVES, A. N. Germinação de sementes de pinho cuiabano sob deficiência hídrica com diferentes agentes osmóticos. Scientia Forestalis, v.36, n.78, p.157-163, 2008.

BRASIL. Ministério da Agricultura, Pecuária e Abastecimento. 2009. Regras para análise de sementes. Ministério da Agricultura, Pecuária e Abastecimento. Secretaria de Defesa Agropecuária. Brasília, DF: Mapa/ACS. 395p.

CONAB - Companhia Nacional de Abastecimento. Acompanhamento da Safra Brasileira de Grãos. v.5, Safra 2017/2018, n.12, Décimo Segundo Levantamento, setembro de 2018, 148p.

CUSTÓDIO, C. C; SALOMÃO, G. R.; MACHADO NETO,

N. B. Estresse hídrico na germinação e vigor de sementes de feijão submetidas a diferentes soluçóes osmóticas. Revista Ciência Agronômica, v.40, n.4, p.617-623, 2009.

FERREIRA, L. G. R.; REBOUÇAS, M. A. A. Influência da hidratação/desidratação de sementes de algodão na superação dos efeitos da salinidade na germinação. Pesquisa Agropecuária Brasileira, v.27, p.609-615, 1992.

HARDEGREE, S. P.; EMMERICH, W. E. Seed germination in response to polyetilene glycol solution. Seed Science and Technology, v.22, p.1-7, 1994.

HILLEL, D. Soil and water: Physical principies and processes. 1.ed. New York: Academic Press, 1971, 288p.

MACHADO NETO, N. B.; CUSTÓDIO, C. C.; COSTA, P. R.; DONÁ, F. L. 2006. Deficiência hídrica induzida por diferentes agentes osmóticos na germinação e vigor de sementes de feijão. Revista Brasileira de Sementes, v.28, n.1, p.142-148.

MARCOS FILHO, J. 2005. Fisiologia de sementes de plantas cultivadas. Piracicaba: FEALQ, 495p.

MORAES, G. A. F.; MENEZES, N. L. Desempenho de sementes de soja sob condiçóes diferentes de potencial osmótico. Ciência Rural, v.33, n.2, p.219-226, 2003.

MUNNS, R. Comparative physiology of salt and water stress. Plant Cell Environment, v.25, n.2, p.239-250, 2002.

PESKE, S. T.; DELOUCHE, J. C. Semeadura da soja em condiçóes de baixa umidade do solo. Pesquisa Agropecuária Brasileira, v.20, n.1, p.69-85, 985.

R - CORE TEAM. 2014. R: A language and environment for statistical computing. R Foundation for Statistical Computing, Vienna, Austria. Disponível em: http://www.R-project.org/.

SANTOS, A. R.; MANN, R.; FERRERA, R. A.; BRITO, A. S. Water pre-hydration as priming for Moringa oleifera Lam. seeds under salt stress. Tropical and Subtropical Agroecossystems, v.14, p.201-207, 2011.

SILVA, J. B.; RODRIGUES, T. J. D.; VIEIRA, R. D. Desempenho de sementes de soja submetidas a diferentes potenciais osmóticos em polietilenoglicol. Ciência Rural, v.36, n.5, p.1634-1637, 2006.

SLAVIK, B. Methods of studing plant water relations. 1.ed. New York: Springer-Verlag, 1974, 449p.

SOUSA, M. A.; SILVA, D. C.; SIMON, G. A. Desempenho de plântulas de melancia submetidas a diferentes níveis de potencial osmótico. Global Science and Technology, v.3, n.2, p.8 - 19, 2009. 
TESTER, M.; DAVÉNPORT, R. Na+ tolerance and $\mathrm{Na}+$ transport in higher plants. Annals of Botany, v.19, n.5, p.503527, 2003.

TOBE, K.; LI, X.; OMASA, K. Seed germination and radicle growth of a halophyte, Kalidium caspicum (Chenopodiaceae). Annals of Botany, v.85, p.391-396, 2000.

VERSLUES, P. E.; AGARWAL, M.; KATIYAR-AGARWAL, S.; ZHU, J.; ZHU, J. K. 2006. Methods and concepts in quantifying resistance to drought, salt and freezing, abiotic stress that affect plant water status. The Plant Journal, v.45, n.4, p.523-539.

VILLELA, F.A.; DONI FILHO, L.; SIQUEIRA, E. L. Tabela de potencial osmótico em funçáo da concentração de polietileno glicol 6000 e da temperatura. Pesquisa Agropecuária Brasileira, v.26, n.11, p.1991. 